\title{
Scheduled By Doctor
}

National Cancer Institute

\section{Source}

National Cancer Institute. Scheduled By Doctor. NCI Thesaurus. Code C107524.

Indicates that an event was planned in advance by a doctor. 